\title{
DETERMINING THE MAINTAINABILITY OF BURNING OVENS FROM CEMENT FACTORY
}

\author{
Teodor VASIU, Adina BUDIUL BERGHIAN, Corneliu BIRTOK BANEASA \\ University POLITEHNICA Timişoara, Engineering faculty of HUNEDOARA, Romania \\ e-mail: teodor.vasiu@ fih.upt.ro
}

\begin{abstract}
For any industrial entity put into operation, it is of interest to its ability to fulfil its mission under certain conditions, at a given time or during a given period of time, assuming that the means of maintenance are provided. This represents availability and is a complex form of system / product quality, as it includes both reliability and maintainability. Availability can be increased by: maximum reliability, maintenance, respectively by maximum maintainability, correct use of equipment / machines, renewal, optimization of reliability and maintainability characteristics, but provided that such balancing does not lead to contradictory solutions. The availability of a product will be higher the more reliable it is and requires less maintenance. It should be borne in mind that in order to ensure a certain level of reliability, maintenance costs must not exceed $10 \ldots 20 \%$ of the purchase price of the product each year [1]. Restoration of reliability to a normal level is achieved through corrective or preventive maintenance. In practice, a compromise is sought between the purchase price, the service imposed and the accepted risk, as in order to achieve availability through reliability, very reliable parts must be used, which cost 5-10 times more than usual [2]. Maintenance-based availability results from the consideration that reliability is a probability of troublefree operation over a period of time. Reliability is technically and financially limited. Defects in the initial period of operation of the product, as well as those in the final period derive from inevitable physical phenomena, and defects in the maturity period have a normal accidental character. In addition, the reliability can deteriorate over time even during storage, thus causing additional damage. Reliability is restored to its normal level through corrective or preventive maintenance, as failures are foreseeable or unpredictable. Product availability is the result of a combination of reliability and maintainability and they support each other. Increasing the maintainability of products leads to increased availability. In this case, the real maintainability of a burning oven of a cement factory was studied, with the aim of finding practical solutions to increase the service life. Achieving the proposed objective required monitoring the operation / failure of such equipment for nine months and statistical processing of the information obtained.
\end{abstract}

KEYWORDS: cement factory, burning oven, maintainability

\section{Introduction}

This introduction has the role of showing the place and importance of burning ovens in the technological flow of obtaining cement. Cement is a fine, grey powder, obtained by grinding clinker, gypsum, as well as additives (slag, limestone, etc.), judiciously dosed. Mixed with a limited amount of water, the cement sets and hardens, giving durability to the concrete or mortar in which it is incorporated. The manufacturing industry has a major role, being inconceivable the development and modernization of human society without the widespread use of cement. Cement production begins in quarries, with the excavation of limestone and clay. They are crushed and then transported to the factory, by conveyor belt systems and/or by rail. Limestone and clay are finely ground together with other materials that bring iron and/or silicon, each of the components being carefully 
dosed and analysed to comply with the flour preparation recipe, which is placed in the oven to obtain the clinker. Raw flour, heated in a rotary kiln to a temperature of up to $1,450{ }^{\circ} \mathrm{C}$ [3], is transformed by sudden cooling into a new, crystalline, granularlooking material called clinker, which is an intermediate - but essential - product in the manufacture of cement. After grinding the clinker, together with well-controlled dosages of gypsum and manufacturing additives (slag, limestone, etc.) at a particularly high fineness, the final product is obtained - cement. On the other hand, the appreciation of the production of cement factories is made according to the capacity offered by the burning oven (clinker). Therefore, any research on them is adequate.

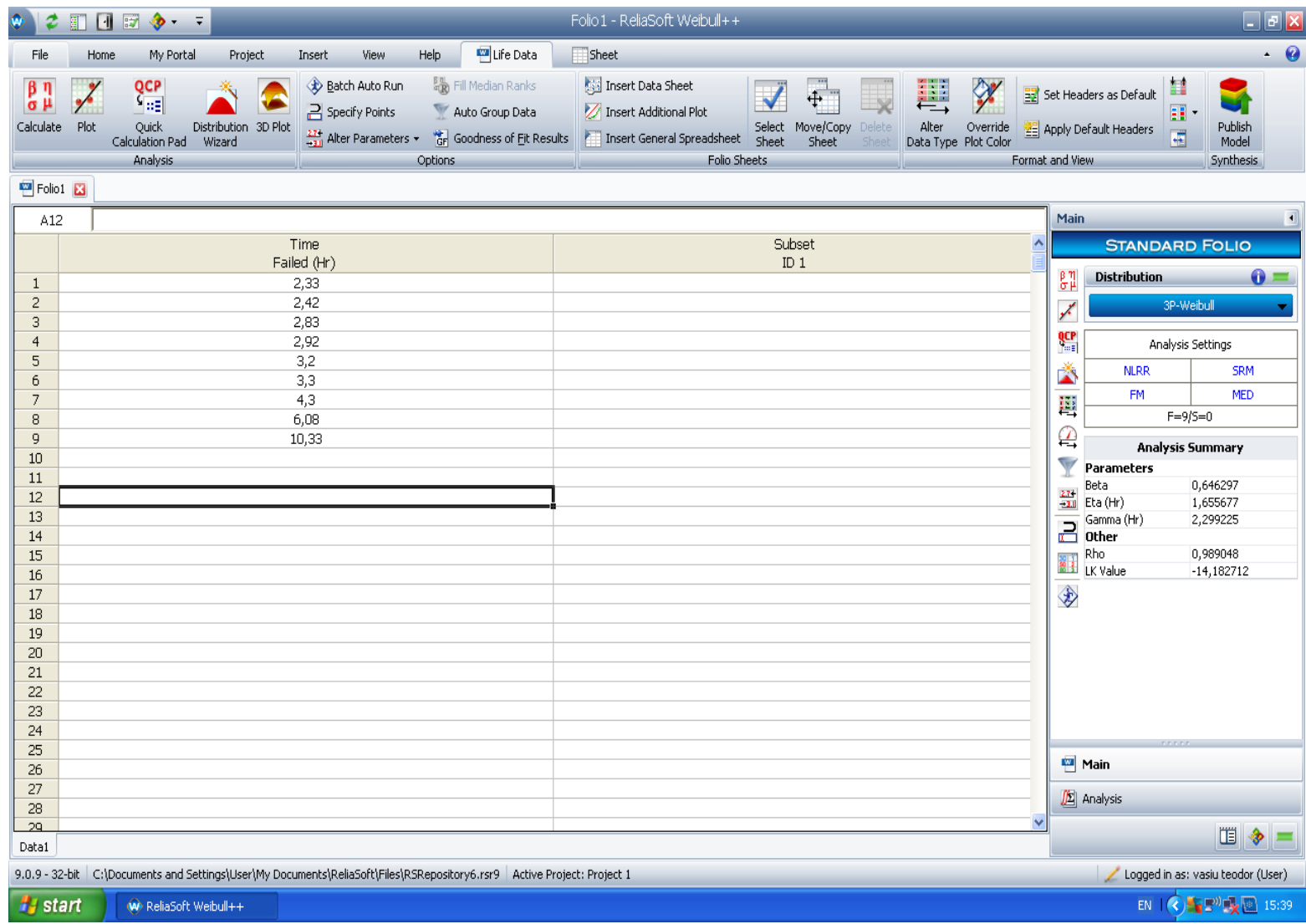

Fig. 1. Maintenance times

\section{Recording and processing of experimental data}

Determining the maintainability of burning ovens requires monitoring the operation of these equipment for as long as possible and recording the downtime due only to the repair of defects. Logistic delay times and administrative delay times are taken into account in the calculation of maintainability, because the real determination of maintainability was wanted. In this case, the follow-up was done daily for nine months, according to the recommendations from [1]. The purpose of this action is to determine the mathematical expression of the maintainability of the oven so that at any time of the repair - other than the recorded values - the probability of restoring the machine is known. This requires the use of laws and techniques for processing mathematical statistics.
Following the application of statistical knowledge, the law of distribution of maintainability is determined, with a certain probability.

The processing of the experimental data was done with the Weibull ++ 9 software of the Reliasoft company [4]. The

maintenance times, introduced in the program, are shown in figure 1 . The software used shows that the distribution law of maintenance times $M(t)$ is Weibull (Figure 2), whose mathematical expression is [5]:

$$
\mathbf{M}(\mathbf{t})=1-\mathrm{e}^{-\left(\frac{\mathbf{t}-\boldsymbol{\gamma}}{\boldsymbol{\eta}}\right)^{\beta}}
$$

in which $\mathrm{t}[\mathrm{Hr}]$ is the repair time. 


\section{THE ANNALS OF "DUNAREA DE JOS" UNIVERSITY OF GALATI \\ FASCICLE IX. METALLURGY AND MATERIALS SCIENCE \\ $\mathrm{N}^{\circ} .2$ - 2021, ISSN 2668-4748; e-ISSN 2668-4756 \\ Article DOI: https://doi.org/10.35219/mms.2021.2.03}

Starting from the idea that the rate of falls is time-dependent (which largely agrees with the development of a wide range of phenomena), Weibull proposes for this indicator the following function:

$$
\mathbf{z}(\mathbf{t})=\frac{\boldsymbol{\beta}}{\boldsymbol{\eta}}\left(\frac{\mathbf{t}-\boldsymbol{\gamma}}{\boldsymbol{\eta}}\right)^{\boldsymbol{\beta}-1}
$$

The three parameters of the Weibull distribution, results from Figure 1 are: the shape parameter (dispersion, slope) $\beta=0.646$; the scale parameter $\eta=$ 1,655 hours and the position parameter (initialization) $\gamma=2,299$ hours.

In the case of the Weibull distribution, the average repair time of the MTR has the expression:

$$
\mathbf{M T R}=\boldsymbol{\eta} \Gamma\left(\frac{1}{\boldsymbol{\beta}}+1\right)
$$

in which $\Gamma$ is the Eulerian integral (Gamma function) which has the expression:

$$
\Gamma(\mathbf{p})=\int_{0}^{\infty} \mathbf{t}^{\mathbf{p}-1} \mathbf{e}^{-\mathbf{t}} \mathbf{d t}
$$

where $\mathrm{p}>0$ is a real parameter. In this case MTR $\approx \eta$ $=1,655$ hours.

The Allan Plait diagram (Figure 2), whose coordinate axes are double - logarithmic, is used to certify the Weibull distribution law and to determine the parameters of this law.

The concavity to the right of the initial curve shows that the studied equipment is repaired most often after accidental falls, a fact that will be seen from Figure 3.

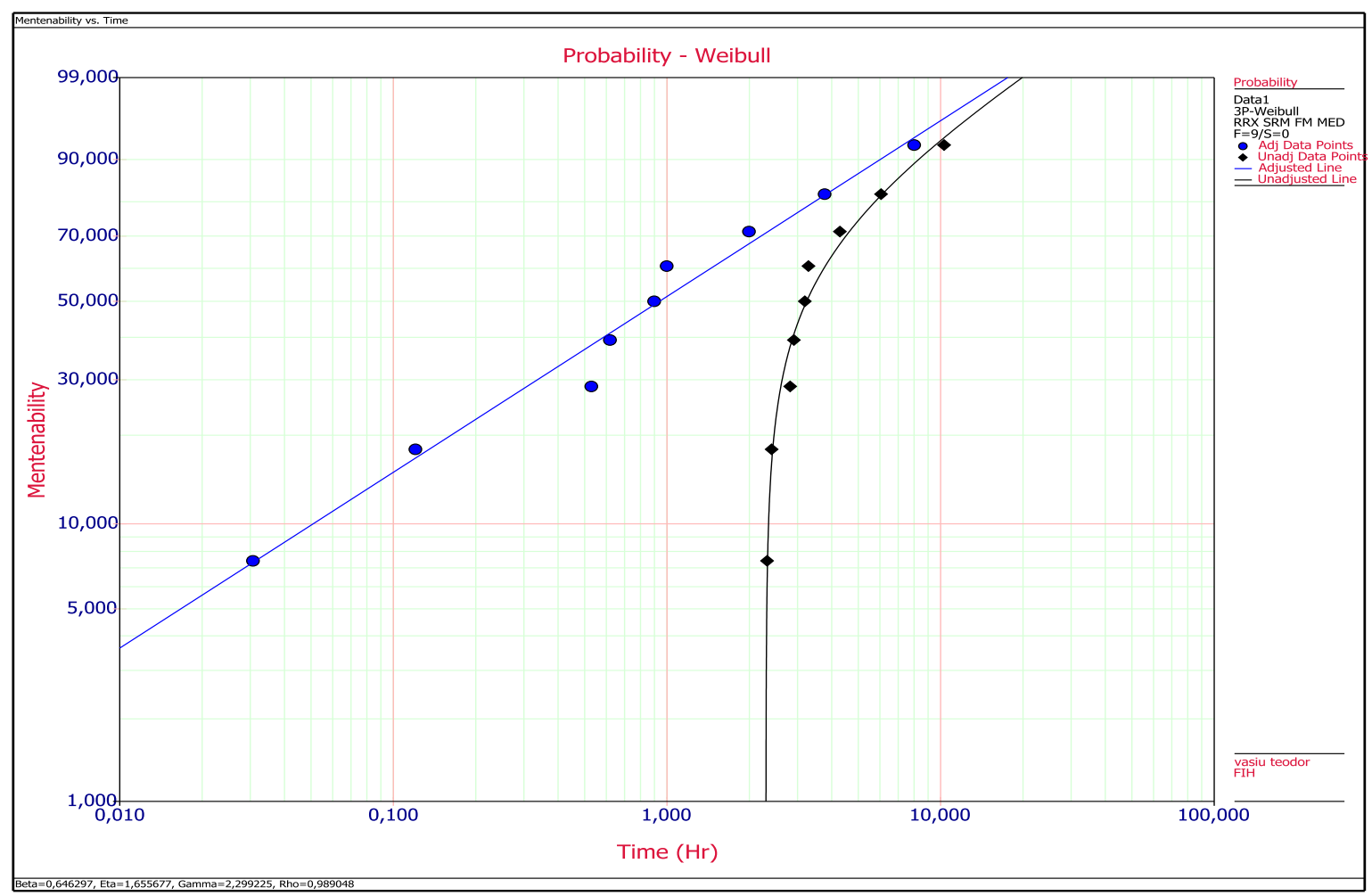

Fig. 2. Allan Plait diagram

\section{Interpretation of the obtained results}

The specialized literature offers few rules for interpreting the values of the statistical parameters of the distribution laws; that is why experience in the field has a major role [6-8].
The graphical representation, in cartesian coordinates, of the expression (1) is shown in Figure 3.

Figure 3 shows that from the moment $t=0$ of the fall to $\mathrm{t}=\gamma=2,299$ hours the maintainability is zero i.e., in this time the probability of restoring the defective oven is zero. The reasons for the delay are related to the fact that the stops are usually accidental, 
in which case it is not possible to anticipate the necessary personnel for the intervention, the volume of materials, spare parts and the duration of the repair. Only after 2,299 hours the chances of repair begin to increase, reaching after about 16 hours that the probability of repairing the furnaces (maintainability) becomes maximum i.e., 1.

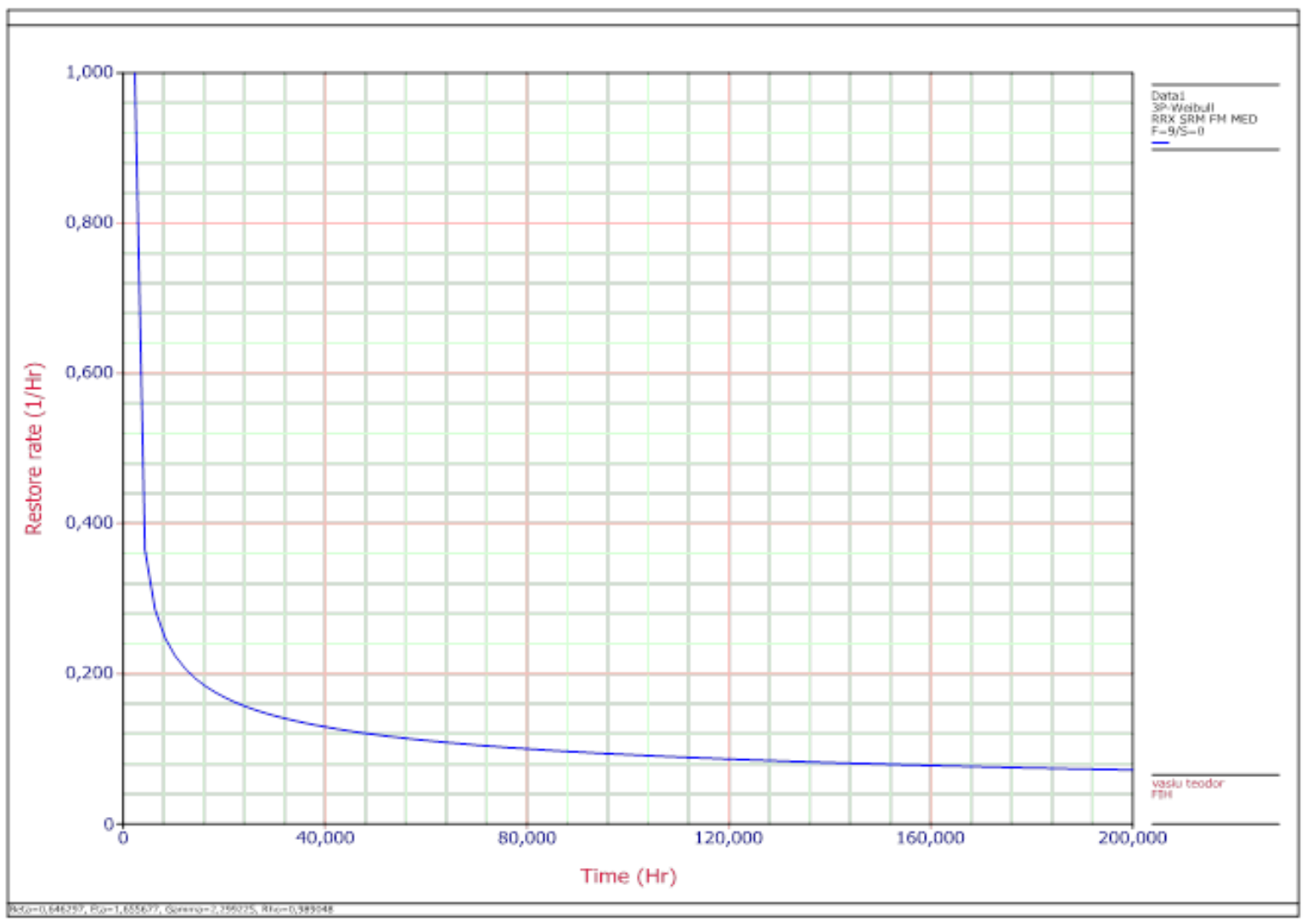

Fig. 3. Maintainability versus time

Although after 16 hours the probability of recovery is maximum, that time should not be considered as a minimum that can be exceeded no matter how much that in any case the maintainability does not decrease. Looking at figure 4 of the variation of the restoration rate over time, it is found that it decreases suddenly at a certain moment, which shows that although the possibility of repair is maximum, it is not done for various reasons that involve some very serious analyses.

The parameter $\beta=0.646<1$, shows that the oven faults start before it is put into operation, which shows that its repairs are done improperly, which must also be analysed very well.

In statistics, the maximum verisimilitude function or the Likelihood function is used to determine the parameters of distribution laws. The method of maximum verisimilitude [5] proposes, for the case studied in the paper, the consideration of a sample that contains the values $t_{1}, t_{2}, \ldots, t_{9}$ of the random variable "repair time". The probability density $\mathrm{f}\left(\mathrm{t}_{\mathrm{i}}, \beta, \eta, \gamma\right), \mathrm{i}=1,2, \ldots, 9$ is known, of the variable "repair time", in which $\beta, \eta$ and $\gamma$ are the parameters of the Weibull distribution law:

$$
\mathbf{f}(\mathbf{t})= \begin{cases}\frac{\beta}{\eta}\left(\frac{t-\gamma}{\eta}\right)^{\beta-1} \mathrm{e}^{-\left(\frac{\mathrm{t}-\gamma}{\eta}\right)^{\beta}} & ; \text { if } \mathbf{t} \geq \gamma \\ 0 & ; \text { if } \mathbf{t}<\gamma\end{cases}
$$

The Likelihood function is:

$$
\mathbf{L k}=\prod_{\mathbf{i}=1}^{9} f\left(\mathbf{t}_{\mathbf{i}}, \boldsymbol{\beta}, \boldsymbol{\eta}, \boldsymbol{\gamma}\right)
$$

The values of the parameters $\beta, \eta$ and $\gamma$ are determined from the condition that the probability function $\mathrm{Lk}$ has the maximum value i.e., the point estimators of the parameters $\beta, \eta$ and $\gamma$ are obtained from the solutions of the equations: 


$$
\left[\frac{\partial \mathbf{L k}}{\partial \boldsymbol{\beta}}\right]_{\hat{\boldsymbol{\beta}}}=\left[\frac{\partial \mathbf{L k}}{\partial \boldsymbol{\eta}}\right]_{\hat{\boldsymbol{\eta}}}=\left[\frac{\partial \mathbf{L k}}{\partial \boldsymbol{\gamma}}\right]_{\hat{\boldsymbol{\gamma}}}=0
$$

However, since the maximum of Lk occurs together with the maximum of the function $\operatorname{lnLk}$, the values of the parameters $\beta, \eta$ and $\gamma$ are more easily determined from the equations: $\left[\frac{\partial \ln \mathbf{L k}}{\partial \boldsymbol{\beta}}\right]_{\hat{\boldsymbol{\beta}}}=\left[\frac{\partial \ln \mathbf{L k}}{\partial \boldsymbol{\eta}}\right]_{\hat{\boldsymbol{\eta}}}=\left[\frac{\partial \ln \mathbf{L k}}{\partial \boldsymbol{\gamma}}\right]_{\hat{\boldsymbol{\gamma}}}=0(8)$

Equations (8) are called Likelihood equations, and the solutions of the system of equations (8) are called maximum Likelihood estimates or maximum probability indicators.

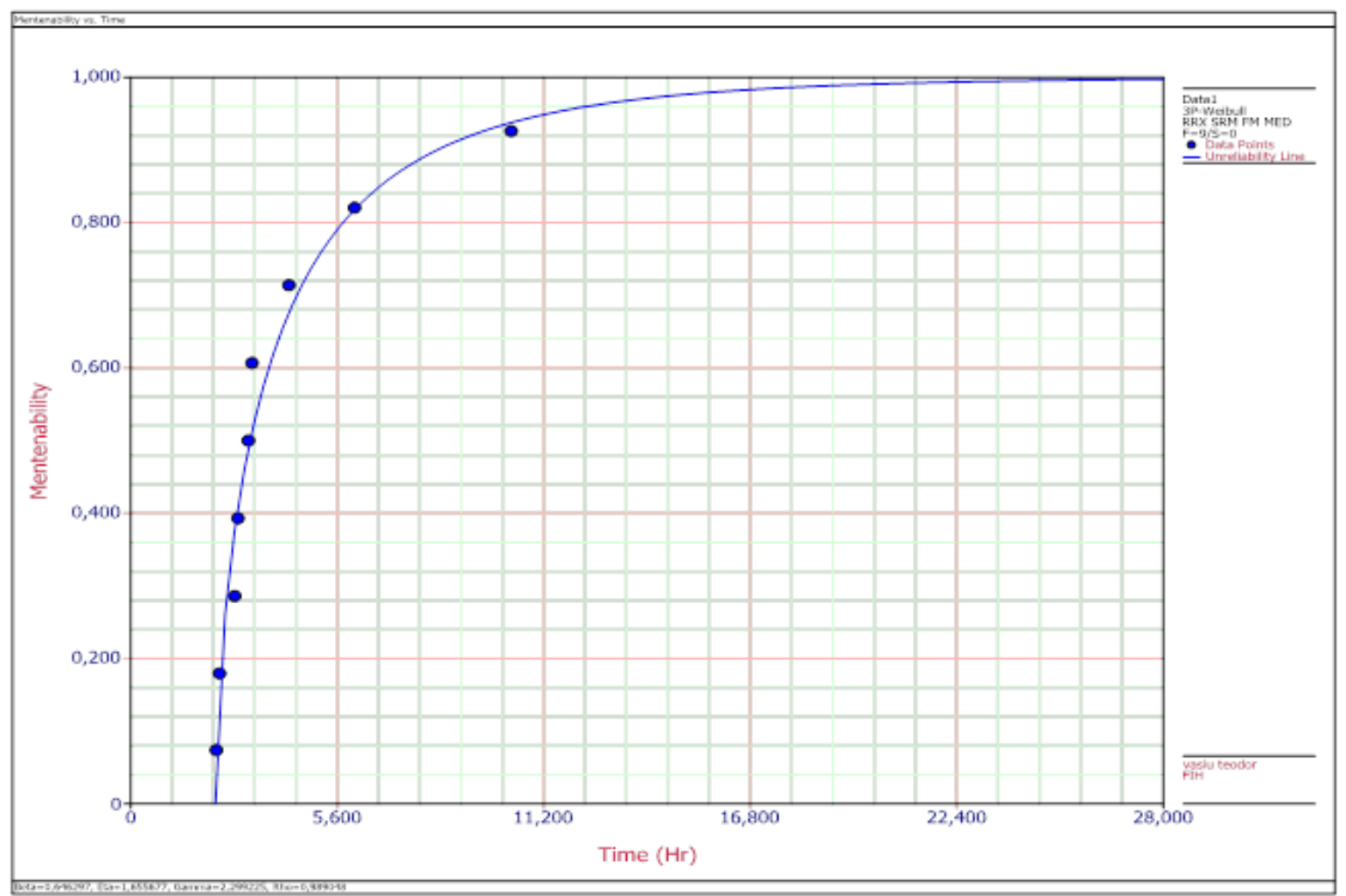

Fig. 4. Restoration rate versus time

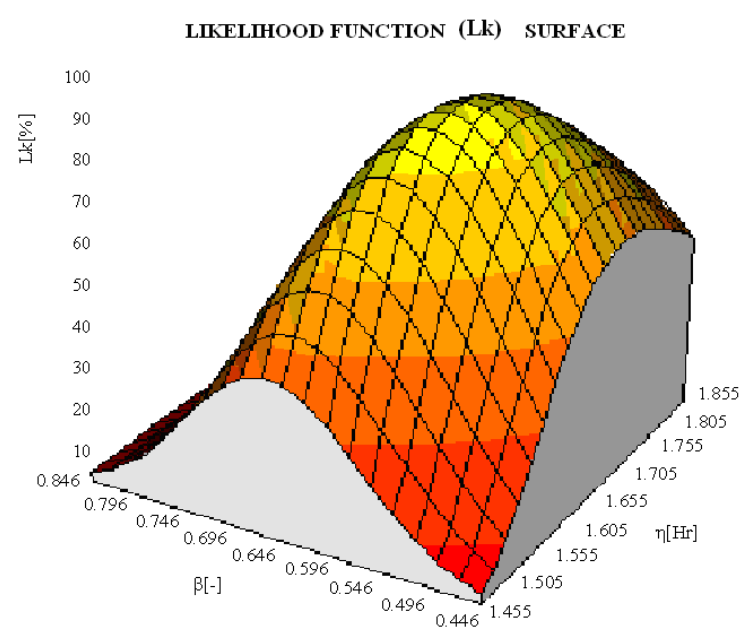

Fig. 5. Likelihood function of maximum verisimilitude
The problem can be asked the other way around: having the parameters $\beta, \eta$ and $\gamma$ you can calculate the Likelihood function and see if it is maximum (100\%) or not. Figure 5 shows that the values $\beta=0.646$ and $\eta$ $=1,655$ hours for $\gamma=2,299$ hours, are the most likely.

\section{Conclusion and proposals to reduce maintenance demands}

In conclusion, drastic measures are required to reduce downtime for maintenance, especially those where maintenance is zero. From a mathematical point of view, it is necessary that the position parameter $\gamma$ be as small as possible, if possible zero. This means knowing very well the defects that may occur, own maintenance personnel (not works in the company) who immediately notice the defect and start repairing it with logistical means prepared in advance. Ideally, $\gamma<0$ i.e., the defect should be found 
before it occurs. This is possible if a coherent system of predictive maintenance i.e., technical diagnosis, is adopted. The introduction of predictive maintenance involves funds allocated for the purchase of specific equipment and last but not least the training of maintenance personnel.

The mean time to repair is MTR $=1,655$ hours, lower than any of the values of the parking times shown in Figure 1. This means that the analysed equipment stops for corrective maintenance, a situation in which the logistic support and the qualified personnel for repair are obtained relatively slowly, not being able to anticipate their size. Here is another reason to introduce predictive maintenance.

Another superior solution for reducing falls is the introduction of a proactive maintenance system. Proactive maintenance is aimed at reducing maintenance demands and maximizing equipment life by systematically eliminating the causes of failures [9].

Within the strategy, several priority objectives can be identified for furnace manufacturers and their users:

- Increasing production capacity by eliminating oven falls; permanent knowledge of the condition of the equipment so as to realistically evaluate the production capacity of the installation;

- Significant reduction of maintenance costs; anticipating and planning maintenance needs;

- Increasing the quality of production and reducing scrap;

- Reducing energy consumption through efficient operation of ovens;

- Reducing the need for spare parts;

- Increasing the safety of the ovens, which leads to the elimination of human accidents and material damage;

- Improving environmental conditions;

- Extending the life cycle of the ovens by eliminating the causes that generated the failure mode;

- Creating a maintenance-production-design team to ensure maximum capacity;

- Improving profit.

Within these objectives, preventive, predictive and proactive technologies act both independently and in conjunction.

Proactive maintenance or maintenance based on determining the root causes of failures uses advanced technologies to prevent the recurrence of failures. Repetitive faults are identified and eliminated by changing the designed parameters and operating conditions.

Valorisation of performance is used to ensure that the new or repaired oven will operate without malfunctions. It is based on the acceptability standards imposed by the equipment suppliers and on the verification of the fulfilment of the requirements of these standards.

The installation and operation of the ovens must be carried out in accordance with the accuracy required by the standards (especially for alignments, balancing), which leads to the extension of the life of the equipment.

Factors that shorten the life of furnaces are identified and significantly reduced by analysing the root causes of failures. If certain machine parts break down with a certain regularity, this fact, although it is accepted as a normality, constitutes the symptoms of much more serious problems. Traditional maintenance solves only the symptoms of problems and accepts frequent repairs as normal.

Root cause analysis is based on a set of analytical and engineering procedures for identifying and correcting developmental problems. The application of such a program leads to remarkable savings and a significant reduction in the failure of the burning ovens of cement plants. As a result of various technologies, it is necessary to redesign, modify and improve existing components or to provide new components. The proactive maintenance aims to determine and analyse the failure rate of the critical components of the furnace and on this basis the adaptation of components with better reliability or redundant elements. Industrial practice shows that elements with high reliability are the best solution.

The implementation of the program requires a balanced strategy between preventive, predictive and proactive maintenance. Within this strategy, predictive maintenance is the point of equilibrium. Knowing the condition of the equipment offered by preventive maintenance, the components are selected that are treated preventively and proactively, respectively, taking into account technical and economic criteria. Usually, the programs start on a small scale, and after the first successes, after 6-12 months the program is extended.

The program will include three stages of implementation:

- initiation, training, primary results;

- extension of preventive maintenance and introduction of proactive maintenance;

- mature proactive maintenance program.

Usually, the first stage the program is considered as an attempt to introduce new concepts. This stage is recommended primarily for equipment that benefits from corrective maintenance (as is the case of the studied oven) or where preventive maintenance is incipient. At this stage, the organizational structure of the maintenance department changes by the emergence of two new groups: the planning team and the reliability improvement team. The duties of the first group must 


\section{THE ANNALS OF “DUNAREA DE JOS” UNIVERSITY OF GALATI \\ FASCICLE IX. METALLURGY AND MATERIALS SCIENCE \\ $\mathrm{N}^{\circ} .2$ - 2021, ISSN 2668-4748; e-ISSN 2668-4756 \\ Article DOI: https://doi.org/10.35219/mms.2021.2.03}

include: coordination of all preventive activities, including technical diagnosis actions; coordination of maintenance activities with production, in order to obtain the least possible impact on availability; coordination of predictive and proactive activities; planning of maintenance works including procedures, tools, spare parts, inspections, calibrations; tracking work orders and costs; updating the equipment history files; evaluation of the trend of the life cycle of the equipment that need improvements; spare parts inventory.

The team of improving the reliability is initially oriented towards the implementation of the preventive maintenance of the furnace and the guidance towards the proactive maintenance. The team consists of one or two specialists in vibration analysis, a specialist in thermography and a specialist in lubricant analysis. The group's responsibilities include: involvement in the direct operation of the furnace and the application of predictive maintenance technologies; providing data on the condition of the furnace to the planning team in order to eliminate unplanned shutdowns; implementation of proactive technologies and respective methods, with identification of repetitive problems; performance monitoring, availability analysis, maintenance costs, quality; identification of schooling needs; identification of parts that need redesign in order to improve reliability.

In the second stage of implementation i.e., the second and third year of the program, several maintenance technologies are added. These technologies include precision alignment, balancing and analysis of the causes of failures. At this stage the attitude of production towards maintenance will change. Management will eliminate production interruptions, and the attitude of employees will be oriented towards preventing and eliminating the causes of failures.
The last stage of program implementation is materialized in the total change of attitude towards the maintenance department. The stage is materialized by an aggressive strategy of eliminating production interruptions and increasing the quality of the product (clinker) by maintaining the performance of the oven in the parameters.

This concept of maintenance based on reliability represents a progress in the development of the maintenance activity, of tightening the links between maintenance and production, the latter being interested in improving the quality and increasing the productivity.

\section{References}

[1]. Baron T., Isac Maniu A., Tovissi L., Niculescu D., Baron C., Antonescu V., Roman I., Calitate şi fiabilitate - manual practic, vol. 1 şi 2 (Quality and reliability - practical manual, vol. 1 and 2), Editura Tehnică, Bucureşti, 1988.

[2]. ***, https://ro.wikipedia.org/wiki/Ciment.

[3]. Cadar I., Clipii T., Tudor A., Beton armat (Reinforced concrete), ediția a 2-a, Editura Orizonturi Universitare, Timişoara, 2004.

[4]. ***, www.reliasoft.com.

[5]. Mihoc Gh., Muja A., Diatcu E., Bazele matematice ale teoriei fiabilităţii (The mathematical foundations of reliability theory), Editura Dacia, Cluj-Napoca, 1976.

[6]. Vasiu T., Fiabilitatea sistemelor electromecanice (Reliability of electromechanical systems), Editura Bibliofor, Deva, 2000.

[7]. Vasiu T., Budiul Berghian A., Reliability of clincher burners from cement industry, Annals of Faculty of Engineering Hunedoara - International Journal of Engineering, Tom XVI, Iss. 3 August 2018.

[8]. Vasiu T., Budiul Berghian A., Determining the reliability of clincher coolers, The Annals of the University of Dunarea de Jos of Galati, Fascicle IX. Metallurgy and Materials Science, no. 3, p. 51-56, 2018.

[9]. Banescu A., Menetenanţa bazată pe fiabilitate - noua viziune pentru îmbunătătirea calitii şi productivităţii (Reliability-based maintenance - the new vision for improving quality and productivity), Asigurarea Calității - Quality Assurance, Anul I, Numărul 1, Ianuarie-Martie, 1995. 